\title{
Asymmetric ramification of deep femoral artery: Incidental detection of an anatomic variation 2 s
}

\author{
Hamit Serdar Başbuğ *, Kanat Özışık \\ Department of Cardiovascular Surgery, Kafkas University Faculty of Medicine, Kars, Turkey
}

\section{A R T I C L E I N F O}

\section{Article history:}

Received 9 November 2016

Received in revised form 26 November 2016

Accepted 29 November 2016

Available online 2 December 2016

\section{Keywords:}

Anatomy

Comparative

Anatomy

Cross-sectional

Femoral artery

\begin{abstract}
A B S T R A C T
The origin of the deep femoral artery (DFA) is most commonly located posterolaterally constituting the $40 \%$ of all studied specimens. Second most common course is the posterior origin (37\%), that is followed by the lateral (12\%), posteromedial (12\%) and medial $(2 \%)$ origins respectively. In this case report, we presented a case with a lateral originated DFA which is the third common anatomic variation. This case is especially important that it demonstrates the branching behaviors of vascular structures may differ between the right and the left limbs creating an asymmetry between the both sides of the same patient. Clinicians should be aware of anatomic variation during the cardiac catheterization, trans-arterial interventions, arteriography and the surgical dissections of the groin region.

(c) 2016 The Society of Cardiovascular Academy. Production and hosting by Elsevier B.V. All rights reserved. This is an open access article under the CC BY-NC-ND license (http://creativecommons.org/licenses/by-nc-nd/4.0/).
\end{abstract}

\section{Introduction}

The proper knowledge of the vascular anatomy, the course and the ramification of the blood vessels of the whole body is very important for the surgeons as well as the interventional cardiologists and radiologists. ${ }^{1}$ A detailed knowledge about the vascular structures in the femoral triangle is especially crucial for a vascular reconstruction involving the groin. The ramification variations of the common femoral artery (CFA) have been known since the days of Andreas Vesalius (1514-1564), a Belgian doctor and anatomist. ${ }^{2}$ However, the variations of the origin and course of the CFA and its major branches have started to be studied genuinely after the invention of vascular imaging and peripheral arteriograms. ${ }^{3}$ The deep femoral artery (DFA) originates mostly from the posterolateral side of the CFA. ${ }^{4}$

The femoral artery (FA) begins behind the inguinal ligament midway between the anterior superior iliac spine and the pubic symphysis as the continuation of the external iliac artery. It descends along the anteromedial thigh in the femoral triangle, passes through the adductor canal and becomes the popliteal artery. The DFA is the largest branch arising from the FA distal to the inguinal ligament. Variations regarding the origin and course of the DFA are especially important in this modern era of interventional cardiology and radiology. ${ }^{1}$

\footnotetext{
it Peer review under responsibility of The Society of Cardiovascular Academy.

* Corresponding author.

E-mail address: s_basbug@hotmail.com (H.S. Başbuğ).

Peer review under responsibility of The Society of Cardiovascular Academy.
}

In this article, we reported a case with a lateral origin of DFA on the left side while the right side reveals a common posterolateral origin. This asymmetric branching of the left DFA deserves to be reported as it shows the different anatomic variations can be present in the same patient. In addition to that, these vascular anatomic variations should strictly be taken into consideration especially before and during the angiographic catheterizations and the surgical explorations of the inguinal region.

\section{Case report}

A 56-year-old male referred to the outpatient clinic with a suspicious complaint of intermittent claudication. He had an ankle-brachial index (1.3) within the normal limits (1-1.4). Palpation of the peripheral pulses revealed no pulse deficit. Color Doppler ultrasound showed triphasic current patterns in all distal arterial vasculatures. Nevertheless, a Computerized Tomography (CT) angiography scan was performed in order not to omit a possible vascular pathology. The CT angiography views revealed normal arterial structure except an interesting variation at the level of CFA bifurcation. The deep femoral arteries of both sides were branching asymmetrically. The origin of the left DFA is slightly higher than the right (Fig. 1). Moreover, the left DFA was arising laterally, whereas the right DFA was arising posteriorly (Fig. 2).

\section{Discussion}

The knowledge about the origin of the DFA has a particular significance in avoiding iatrogenic traumas while performing the CFA 


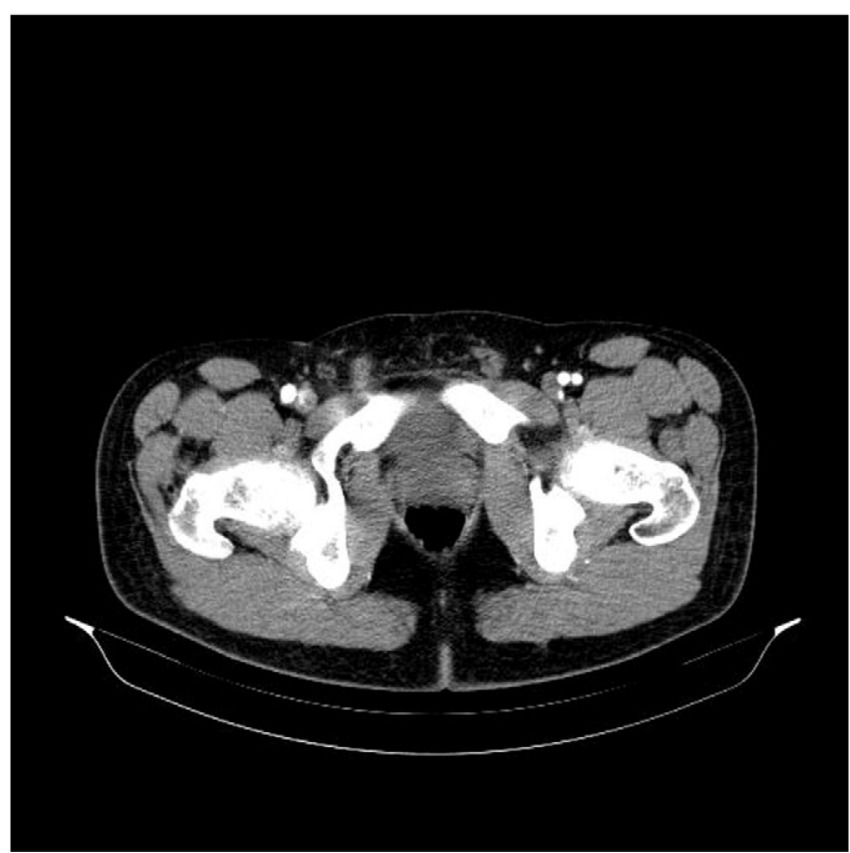

Fig. 1. The Computerized Tomography Angiography scan demonstrates the left deep femoral artery is branching above the level of the contralateral side.

punctures and surgical groin explorations. The average distance of the DFA origin from the midpoint of the inguinal ligament is approximately $47.5 \mathrm{~mm}$ ( 0 to $80 \mathrm{~mm})^{2,3}$ There is a slight difference in the inguinal ligament distance between the right and left groins. ${ }^{3}$ In only one specimen out of one hundred, DFA arises at the level of inguinal ligament and the $70 \%$ of the DFAs arise between 30 and $60 \mathrm{~mm}$ below the midpoint of the inguinal ligament. ${ }^{2}$

The most common course of the DFA is posterolateral, representing $40 \%$ of the studied specimens. The posterior origin was found in $37 \%$, lateral branching in $12 \%$, posteromedial in $9 \%$ and the medial origin was found in $2 \%{ }^{2}$ The average width of the DFA is $5.5 \mathrm{~mm}$ (4 to $9 \mathrm{~mm}$ ), and the median width of the CFA is $12 \mathrm{~mm}$ ( 8 to $16 \mathrm{~mm}){ }^{2,4}$ However, hypertrophic DFAs were also encountered with a nearly the same diameter with the CFA. ${ }^{5}$ An anterior origin of the DFA was never seen so far. ${ }^{2}$

Although there is no enough information in the available literature about the asymmetric take off of the lower extremity vasculature, clinicians should pay attention on this issue before any intervention. Beyond reminding us that the two halves of the body can behave differently, recognition of this anatomic variations has a significant clinical

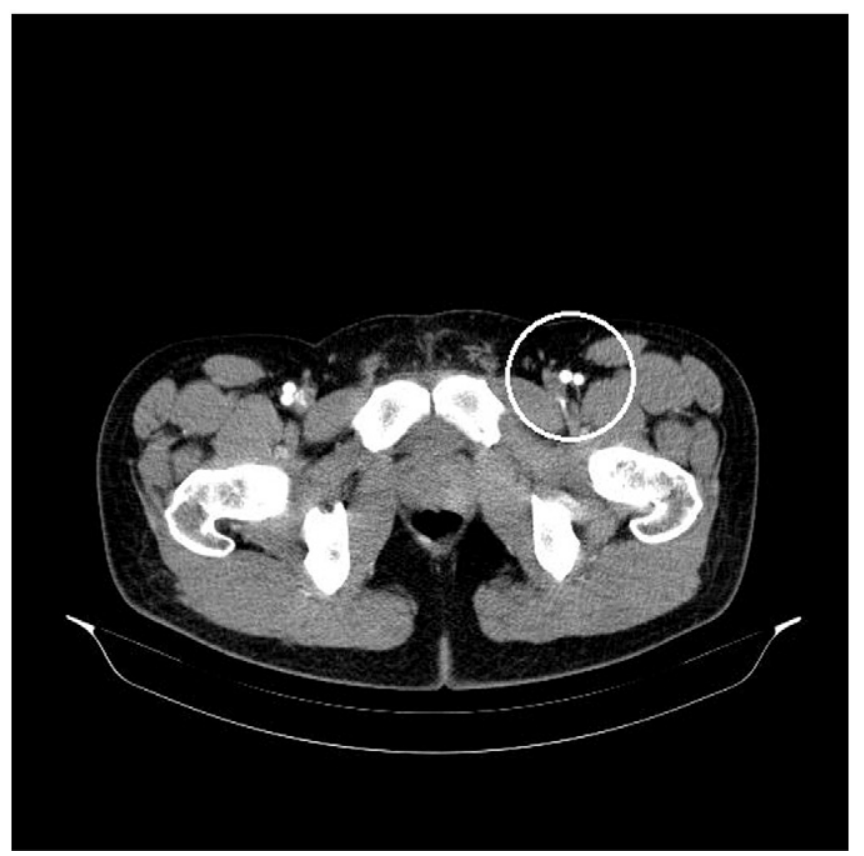

Fig. 2. The Computerized Tomography Angiography scan demonstrates the deep femora artery branching asymmetry between the right and the left deep femoral arteries.

importance for the preoperative decision and predilection of the precise surgical and interventional approaches. The knowledge of the branching site and the course of the DFA also helps in avoiding iatrogenic arteriovenous fistula while performing the femoral artery punctures during interventional procedures.

\section{References}

1. Shiny Vinila BH, Sridevi NS, Kumaraswamy RA. A study on the internal diameter of femoral artery and level of origin of profunda femoris artery. Int J Biol Med Res 2013;4(1):2867-2869.

2. Siddharth P, Smith NL, Mason RA, Giron F. Variational anatomy of the deep femoral artery. Anat Rec 1985;212(2):206-209.

3. Dixit DP, Mehta LA, Kothari ML. Variations in the origin and course of profunda femoris. J Anat Soc India 2001;50(1):6-7.

4. Bannister LH, Berry MM, Collins P. Gray's anatomy. Cardiovascular System. 38th ed. Churchill Livingstone: Medical Division of Longman Group, UK Ltd.; 1995. p. $1566-1568$.

5. Basbug HS, Bitargil M, Gok M, Gocer H, Gunerhan Y, Ozisik K. Hypertrophic profunda femoral artery mimicking dual common femoral artery: a case report. J Cardiovasc Surg 2015;3(2):51-53. 